\title{
Can the exposure of Apis mellifera (Hymenoptera, Apiadae) larvae to a field concentration of thiamethoxam affect newly emerged bees?
}

\author{
Priscila Sepúlveda Friol*, Aline Fernanda Catae, Daiana Antonia Tavares, Osmar Malaspina, \\ Thaisa Cristina Roat
}

UNESP - Univ. Estadual Paulista, campus de Rio Claro, Instituto de Biociências, Departamento de Biologia, Centro de Estudos de Insetos Sociais, Rio Claro, SP, Brazil

\section{H I G H L I G H T S}

- Thiamethoxam, a nenonicatinoid insecticide, can affect non-target insects, as bees.

- It's effects on bees were investigated after exposure during the larval phase.

- Larval and pupal survival and percentage of emergence were not altered.

- Ultrastructural alterations were observed on organs of newly emerged bees.

- The exposure to thiamethoxam can cause cellular alterations in organs of adult bees.

\section{A R T I C L E I N F O}

\section{Article history:}

Received 10 April 2017

Received in revised form

14 June 2017

Accepted 27 June 2017

Available online 29 June 2017

Handling Editor: David Volz

\section{Keywords:}

Bees

Neonicotinoid

Ulstrastrucuture

Midgut

Malpighian tubules

Mushroom body

\begin{abstract}
A B S T R A C T
The use of insecticides on crops can affect non-target insects, such as bees. In addition to the adult bees, larvae can be exposed to the insecticide through contaminated floral resources. Therefore, this study aimed to investigate the possible effects of the exposure of $A$. mellifera larvae to a field concentration of thiamethoxam $(0.001 \mathrm{ng} / \mu \mathrm{L}$ thiamethoxam $)$ on larval and pupal survival and on the percentage of adult emergence. Additionally, its cytotoxic effects on the digestive cells of midgut, Malpighian tubules cells and Kenyon cells of the brain of newly emerged A. mellifera bees were analyzed. The results showed that larval exposure to this concentration of thiamethoxam did not influence larval and pupal survival or the percentage of adult bee emergence. However, this exposure caused ultra-structural alterations in the target and non-target organs of newly emerged bees. The digestive cell of bees that were exposed to the insecticide exhibited a basal labyrinth without long and thin channels and compromised mitochondria. In Malpighian tubules cells, disorganized basal labyrinth, dilated mitochondria with a deformed shape and a loss of cristae, and disorganized microvilli were observed. The results showed that the exposed bees presented Kenyon cells with alterations in the nucleus and mitochondria. These alterations indicate possible tissue degeneration, demonstrating the cytotoxicity of thiamethoxam in the target and nontarget organs of newly emerged bees. Such results suggest cellular organelle impairment that can compromise cellular function of the midgut cells, Malpighian tubules cells and Kenyon cells, and, consequently, can compromise the longevity of the bees of the whole colony.
\end{abstract}

(C) 2017 Elsevier Ltd. All rights reserved.

\section{Introduction}

Over the past decade, there has been increasing concern about

\footnotetext{
* Corresponding author. UNESP - Centro de Estudos de Insetos Sociais, Avenida 24-A, n.1515 - Bela Vista, 13.506-900 Rio Claro, SP, Brazil.

E-mail addresses: priscilasfriol@yahoo.com.br (P.S. Friol), aline_catae@hotmail. com (A.F. Catae), daianazoo@yahoo.com.br (D.A. Tavares), malaspin@rc.unesp.br (O. Malaspina), thaisaroat@yahoo.com.br (T.C. Roat).
}

the global decline of pollinators. Many studies have shown the decline of honeybee populations, and the protection of these pollinators is being implemented in many countries (Potts et al., 2016). Colony losses observed in some parts of the world can be due to pathogens (Neumann and Carreck, 2010), insecticides (Henry et al., 2012), weather, habitat loss (Potts et al., 2010; vanEngelsdorp and Meixner, 2010), or interactions among these factors (Goulson et al., 2015). At the same time, growing evidence shows that insecticides have inevitably caused adverse behavioral and 
physiological effects on individual bees and colonies (Henry et al., 2012; Di Prisco et al., 2013).

Not only do forager bees come into contact with toxic substances that are present in the environment, but also those who perform intracolonial activities and larvae that can feed on pollen and nectar that have been contaminated with insecticides. Therefore, it is necessary to understand the possible consequences of the exposure of larvae to xenobiotics and how it can affect bee development (Rortais et al., 2005; Desneux et al., 2007; Blacquière et al., 2012).

Neurotoxic insecticides such as neonicotinoid stand out among the most used pesticides today (Tomizawa and Casida, 2003). A member of this class of insecticides is thiamethoxam, which is used on various crops, including sugarcane, citrus, coffee, rice and pineapple, via an aerial or terrestrial application (Nondillo et al., 2007).

Neonicotinoids acts systemically in the plant and can contaminate the pollen and nectar that are used by bees as food resources (Bonmatin et al., 2003). Thus, through the metabolization route, the insecticide is ingested along with the food and comes into contact with non-target organs (midgut and Malpighian tubules) besides reaching the target organ (brain).

The midgut is a non-target organ of thiamethoxan whose functions include the digestion and absorption of food (Kakamand et al., 2008; Cruz et al., 2010; Oliveira et al., 2013). The digestive system of the bees is divided into three regions: anterior intestine; midgut, and posterior intestine. The midgut is composed of three cell types: digestive, endocrine and regenerative cells. Digestive cells are the most abundant and produce digestive enzymes as well as absorb digestion products (Neves et al., 2003; Cruz-Landim, 2009).

After the passage of the contaminated food through the intestine, the active ingredient reaches the hemolymph and can be transported until to target organ (the brain) as well as be absorbed by the Malpighi tubules for excretion. The excretory system is primarily responsible for maintaining homeostasis. In insects, it is most often composed of a variable number of Malpighi tubules, which play an important role in the detoxification process since it actively promotes the elimination of substances that have not yet been metabolized and/or are in excess in the body (Chapman, 1998).

Insecticides absorbed in midgut by oral administration will be translocated for hemolymph, which is immediately bombed to head by dorsal heart and the great amount of absorbed insecticide reach very fast the brain. According to Antunes-Kenyon and Kennedy (2001), thiamethoxam acts as an agonist for nicotinic acetylcholine receptors. Thus, acetylcholine is mimicked by the molecule, which binds to the nicotinic receptor site and block it. Due to this blockage, there is a buildup of acetylcholine, thus causing paralysis and death (Rancan et al., 2006).

With the abnormally extended activation of acetylcholine receptors, the central nervous system enters a state of hyperexcitability due to the continuous and uncontrolled transmission of nerve impulses. The symptoms resulting from the neonicotinoid intoxication include nervous system collapse, tremors, and death (Faria, 2009).

In the central nervous system, the mushroom body consists of innumerable neurons, such as the Kenyon cells, which form the chalices with their dendrites, the peduncle and the lobes $(\alpha, \beta$, and $\gamma$ ) with their axons (Farris, 2005; Fahrbach, 2006). As paired structures located symmetrically on each side of the protocerebrum, the mushroom bodies are described as being the center of the neural basis for the storage and processing of olfactory information (Davis, 2001; Gerber et al., 2004); it is also involved in other forms of learning (Liu et al., 1999; Mizunami et al., 1993).
As the brains are the target of the neonicotinoid insecticides, several studies have shown that these compounds can affect the behavior of bees. Several behavioral changes are observed, including changes in olfactory memory, loss of orientation, and trouble in foraging activities (Decourtye et al., 2003, 2004; Colin et al., 2004; Yang et al., 2008; Schneider et al., 2012).

Africanized $A$. mellifera bees are important pollinators that maintain the biodiversity of the ecosystem, which enabled the production of diverse cultures and is essential for human life as well as for the economy of the country. However, due the increasing agricultural activities in recent times, the use of pesticides has multiplied in order to control pests and have likely affected the bees, which are non-target insects.

Most studies about the effects of pesticides on bees emphasize the adult individuals present in the colony; therefore, there is currently a lack of studies regarding the larvae and the possible consequences that exposure during the larval stage can have on their adult stage, because the larvae is tasked with ensuring the viability and survival of the colony.

Fipronil is an example of an insecticide that can cause toxic effects on the organs of bees, changing several structures that are important for the correct functioning of the body of the insect. Cruz et al. (2010) found that sublethal doses of fipronil caused alterations at the ultrastructural level in the midgut, Malpighian tubules and silk glands of $A$. mellifera.At low levels ( $1 \mathrm{ppm}$ ), dimethoate decreases the foraging activity of bees (Waller et al., 1979) and may, together with malathion, lead to morphogenic defects in adults that were exposed to the product during the larval phase (Atkins and Kellum, 1986), thus affecting the ability of adult bees to perform their tasks, such as foraging. Jacob et al. (2014) analyzed the sublethal effects of the insecticide fipronil in the mushroom bodies of stingless Scaptotrigona postica worker bees and observed through TEM analysis the presence of ultrastructural alterations in Kenyon cells from bees following both oral and topical exposure that are characteristic of cellular death.

Therefore, it is important to determine if the exposure of Africanized honey bee larvae to a field concentration of thiamethoxam can alter the survival of bees during the larval and pupal stage as well as the percentage of adult bee emergence. In addition, this study aimed to evaluate the cytotoxicity of thiamethoxam to the midgut, Malpighian tubules and mushroom bodies of newly emerged bees after exposure during the larval stage to this pesticide. Through this analysis, it is possible to report the morphological alterations in the tissues of these bees, which will contribute to the understanding of the effects of thiamethoxam in non-target and target organs, and therefore, aid in the creation of strategies and arguments to ensure the preservation and protection of bees.

\section{Material and methods}

\subsection{Honey bee breeding and collection}

Larvae of Africanized A. mellifera were collected from the apiary of the Institute of Biosciences of Rio Claro in the Department of Biology at the University of São Paulo State (UNESP) in Rio Claro, SP, Brazil. Three colonies in ideal conditions for collection were selected. The honeybee larvae were reared in vitro using the method described by Aupinel et al. (2005, 2007) and the recommendations of the Organisation for Economic Co-operation and Development (OECD, 2013).

A 48-well microplate was filled with sterile dental cotton impregnated with $500 \mu \mathrm{L}$ of an aqueous solution containing 15\% glycerol and $0.2 \%$ sodium dichloroisocyanurate, with the purpose of maintaining humidity and avoiding possible contamination. A plastic queen-starter-cell was placed in the interior of each well, 
which had been previously sterilized for 30 min with the same sodium dichloroisocyanurate solution and dried in ultraviolet light. To obtain first instar larvae, empty combs were placed inside a beehive for queen laying. A total of 96 larvae from each of the 3 different colonies were used, totaling 288 larvae for each group (exposed and control). Thus, 576 first instar larvae (no more than $24 \mathrm{~h}$ old) were collected and transferred to the plastic queenstarter-cell containing $20 \mu \mathrm{L}$ of diet A (see below). Microplates containing the plastic queen starter cells were kept throughout the experiment in a sealed box at a temperature of $34 \pm 2{ }^{\circ} \mathrm{C}$ and a relative humidity of $90 \pm 5 \%$ in the dark. The larvae were fed for 6 days.

\subsection{Larval feeding}

Three types of diets (A, B and C) containing different concentrations of nutrients were used to meet the nutritional requirements of each larval stage.

On the first day of in vitro rearing, each larva was fed with $20 \mu \mathrm{L}$ of diet A containing $50 \%(\mathrm{w} / \mathrm{w})$ royal jelly and $50 \%(\mathrm{w} / \mathrm{w})$ of an aqueous solution (distilled water) containing $24 \%$ sugar (D-glucose and D-fructose) and $2 \%$ yeast extract. On the 2 nd day, the larvae were not fed, in accordance with the method adopted and validated by Aupinel et al. (2005, 2007). This period was necessary in order to acclimate the larvae to laboratory conditions. On the third day, the larvae were fed with $20 \mu \mathrm{L}$ of diet B containing 30\% sugar (D-glucose and D-fructose) and 3\% yeast extract; or 36\% sugar (D-glucose and Dfructose) and $4 \%$ yeast extract. For the fourth, fifth and sixth days, the larvae were fed, respectively, $30 \mu \mathrm{L}, 40 \mu \mathrm{L}$ and $50 \mu \mathrm{L}$ of diet C, which contained $36 \%$ sugar (D-glucose and D-fructose) and $4 \%$ yeast extract.

After the sixth day (d-6), during the pupation period (d-7 to d15 ), the temperature was maintained by the $\mathrm{RH}$ was altered to $80 \%$ to simulate the conditions of the colony. On d-15, the queen cells were removed from the plates and placed inside plastic pots containing food that consisted of sugar and honey 1:1 (w/w) and water. The pots were conditioned in a BOD incubator at an $\mathrm{RH}$ of $70 \%$. Emergent bees were defined as the bees that left the interior of the queen cells.

\subsection{Acute sublethal exposure to thiamethoxam}

For the sublethal exposure of bees, a concentration of $0.001 \mathrm{ng} /$ $\mu \mathrm{L}$ of thiamethoxam was chosen. This concentration was selected based on the residual amounts found in the field; for example, on the nectar and pollen, which have values of approximately 1-53 $\mu \mathrm{g} / \mathrm{kg}$ (Mullin et al., 2010; Stoner and Eitzer, 2012; Pilling et al., 2013; Krupke et al., 2012). On d-4 of the experiment, the larvae were exposed to thiamethoxam through $30 \mu \mathrm{L}$ of contaminated diet. For contamination, a stock solution of $1.000 \mathrm{ng}$ of thiamethoxam $/ \mu \mathrm{L}$ of acetone + water in the ratio of $1: 9$ was made. Subsequently, from the stock solution, a cascade dilution was done using the previously prepared diet $\mathrm{C}$ as the solvent; a $3 \times$ concentrated solution was achieved, which was directly added to the larval food (diet C) to obtain a concentration of $0.001 \mathrm{ng} / \mu \mathrm{L}$. The larval intake was $0.03 \mathrm{ng} / \mu \mathrm{L}$. Larval and pupal mortality was observed daily with the aid of a stereomicroscope.

\subsection{Analysis of larval and pupal survival and percentage of adult emergence}

After the acute sublethal exposure to thiamethoxam during the larval phase and metamorphosis, the larval and pupal mortality was observed daily with the aid of a stereomicroscope. The percentage of emergence was also observed. The data were analyzed using the statistical R Development Core Team software (2015). To evaluate the influence of thiamethoxam on larval and pupal survival, the data were analyzed using the Cox proportional hazards regression model (survival package), and a significant difference was considered when $P<0.05$.

The influence of thiamethoxam on emergence success was analyzed by a chi-square test $\mathrm{R}$ function (Chisq.test) that makes pair-wise comparisons between the exposed and control groups, with $1 \mathrm{df}$ and $P<0.001$.

\subsection{Transmission electron microscopy (TEM) of organs of newly emerged bees}

After the acute sublethal exposure to thiamethoxam during the larval phase and at the end of the post-embryonic development, 12 newly emerged worker bees of Africanized A. mellifera were collected from the exposed and the control groups to ultrastructural analysis of the organs.

Midguts, Malpighian tubules and brains of exposed and control bees were removed in buffer solution containing $20 \mathrm{mM} \mathrm{Na} 2 \mathrm{HPO} 4 /$ $\mathrm{KH} 2 \mathrm{PO} 4$, pH $7.41130 \mathrm{mM}$ of $\mathrm{NaCl}$ and fixed in modified Karnovsky (4\% paraformaldehyde, $2.5 \%$ glutaraldehyde in $0.1 \mathrm{M}$ sodium cacodylate buffer, $\mathrm{pH} 7.2$ ), during $2 \mathrm{~h}$ at 4C. Once fixed, the organs were washed in the same buffer and postfixed in $1 \%$ osmium tetroxide in the same buffer for $2 \mathrm{~h}$ at room temperature and again washed in the buffer. The post-fixed organs were contrasted in $2 \%$ uranyl acetate in $10 \%$ acetone for $2 \mathrm{~h}$ and then dehydrated in a standard acetone series. The material was embedded in Epon-Araldite resin. Ultrathin sections cut on a Porter Blum ultramicrotome MT2 were stained with lead citrate for $15 \mathrm{~min}$. The material was examined under the transmission electron microscopy (JEOL-JEM1011), no NAP/MEPA - Núcleo de Apoio à Pesquisa em Microscopia Eletrônica Aplicada a Agricultura - ESALq em Piracicaba-SP.

\section{Results}

\subsection{Analysis of larval and pupal survival as well as the percentage of emergence}

It was observed that there was no significant difference in larval survival between the group exposed to thiamethoxam and the control group, as shown in Fig. 1 (Cox model $P>0.05$ ).

Fig. 2 shows the pupal mortality during the bioassays. The group exposed to thiamethoxan during the larval phase did not show a significant difference in pupal survival compared to the pupae from the control group (Cox model $P>0.05$ ).

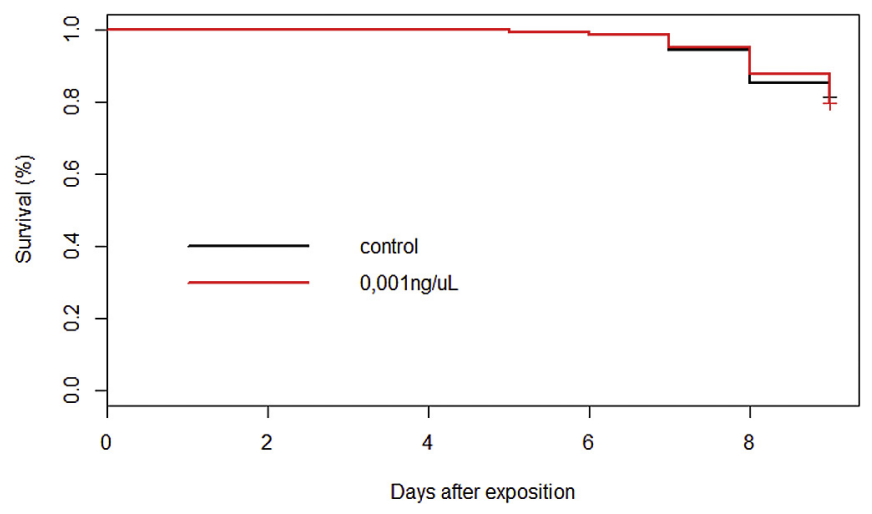

Fig. 1. Effect of a field concentration of thiamethoxam on the survival of Africanized A. mellifera larvae. The data indicate the survival percentage of $A$. mellifera larvae in the days after exposure to thiamethoxam (Cox model $P>0.05$ ). 


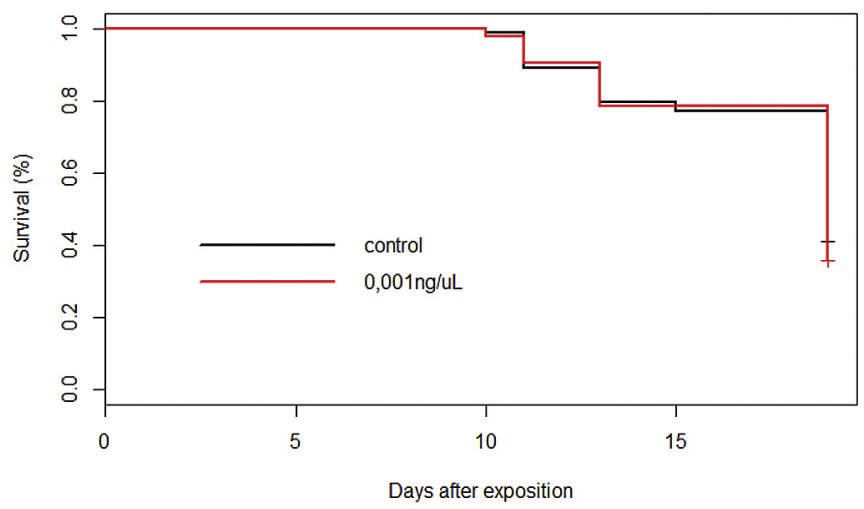

Fig. 2. Effect of a field concentration of thiamethoxam on the survival of Africanized A. mellifera pupae. The data indicate the survival percentage of $A$. mellifera pupae in the days after exposure to thiamethoxam (Cox model $P>0.05$ ).

The percentage of adult bee emergence was calculated from the number of pupae in each experimental group. According to the results, it was observed that the exposed group and control group showed a similar percentage of adult emergence, and there was no significant difference in this parameter between the exposed group and the control group, as shown in Fig. 3 Chi-square test with $1 \mathrm{df}^{*}$ $(P \leq 0.001)$.

\subsection{Transmission electron microscopy}

\subsubsection{Midgut}

The analysis performed in the digestive cells of midgut of newly emerged $A$. mellifera bees reared in vitro showed that the control group exhibited a midgut with the typical ultrastructural characteristics of this organ (Fig. 4A). The digestive cells showed nuclei with a shape from oval to spherical, the interior of the nucleus showed decondensed chromatin (euchromatin) while some regions presented condensed chromatin (heterochromatin) around the nuclear envelope, and an evident nucleolus was observed (Fig. 4A). The mitochondria possessed cristae, and its morphology remained preserved (Fig. 4C); additionally, the basal labyrinth exhibited a typical morphology with long and thin channels (Fig. 4E).

However, the ultrastructure of the digestive cells of newly emerged $A$. mellifera bees after exposure to thiamethoxam during

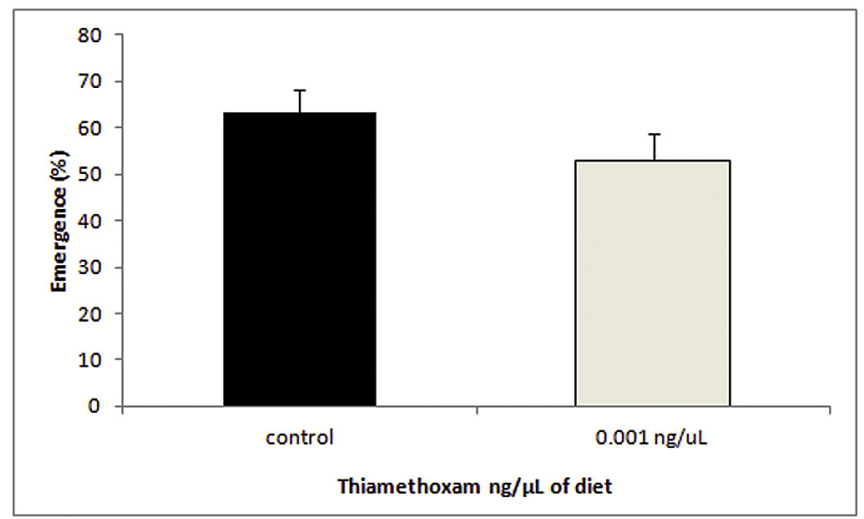

Fig. 3. Effect of thiamethoxam on the emergence success of honeybee adults. The percentage of emergence was calculated from the number of pupae in each experimental group: (i) control, $n=63$; and (ii) $0.001 \mathrm{ng} / \mu \mathrm{L}, n=75$. The comparisons between the exposed groups and controls were done with the Chi-square test with $1 \mathrm{df}$ $(P \leq 0.001)$. Bars represent the mean \pm standard deviation of 3 replicates. the larval phase showed alterations in the ultrastructure of this organ when compared to the control group (Fig. 4B). The nucleus became irregular (Fig. 4B), the mitochondria were dilated with a loss of cristae and matrix (Fig. 4D), and the basal labyrinth showed the absence of long and thin channels (Fig. 4F).

\subsubsection{Malpighian tubules}

The Malpighian tubules of bees from the control group showed structural integrity (Fig. 5A) and spherical-shaped nuclei; the interior of the nucleus was filled with euchromatin with some regions presenting heterochromatin around the nuclear envelope, and the presence of a nucleolus was observed (Fig. 5A). Mitochondria exhibited cristae and were found throughout the cell, with a higher concentration in the apical region and within the microvilli (Fig. 5E); additionally, intact microvilli were observed (Fig. 5G).

The Malpighian tubules of bees from the exposed group showed nuclei with similar morphology as that observed in the control group, (Fig. 5B). The basal labyrinth was disorganized with a loss of folds in the plasma membrane when compared to the control group, and there were mitochondria observed in the region (Fig. 5D). The mitochondria were very dilated and exhibited a loss of cristae (Fig. 5F). Parts of the microvillus were lost, showing structural disorganization in this structure (Fig. $5 \mathrm{H}$ ).

\subsubsection{Mushroom bodies}

The mushroom body of newly emerged $A$. mellifera bees reared in vitro presented Kenyon cells with typical ultrastructural characteristics (Fig. 6A), such as a spherical-shaped nucleus that occupied a large part of the cell; a perinuclear space without expansion; the interior of the nucleus was filled with decondensed chromatin (euchromatin) while some regions presented condensed chromatin (heterochromatin) around the nuclear envelope; the presence of an evident nucleolus (Fig. 6C); and elongated mitochondria throughout the cytoplasm with visible cristae (Fig. 6E).

Newly emerged $A$. mellifera bees after exposure to thiamethoxam during the larval stage showed evident alterations in the ultrastructure of the Kenyon cells when compared to the control group (Fig. 6B). The nucleus of these cells showed an irregular shape and small size compared to the control group. The perinuclear space was dilated; however, the interior of the nucleus remained filled by decondensed chromatin (euchromatin) while some regions around the nuclear envelope presented condensed chromatin (heterochromatin), which was similar to the control group (Fig. 6D). Mitochondrial alterations were also observed, with varied morphology and the loss of some cristae (Fig. 6F).

\section{Discussion}

During foraging activities, bees may come into contact with insecticides in the field. Through the collection of contaminated floral resources, bees are, thus able to carry insecticide residues into the hive and contaminate the larvae. The results found in the present study showed that during the in vitro larval development of Africanized A. mellifera, the field concentration of $0.001 \mathrm{ng} / \mu \mathrm{L}$ thiamethoxam did not interfere with the survival of larvae and pupae or with the percentage of emerged adult bees.

A possible reason for this result is that the larvae were exposed to a field concentration that was low (intake of $0.03 \mathrm{ng} / \mu \mathrm{L}$ per larva), and higher concentrations are required to cause mortality. Tavares et al. (2015) evaluated the sublethal effects of thiamethoxam in larvae, pupae and newly emerged workers of A. mellifera exposed to this insecticide during the larval stage. It was observed that the sublethal concentration of $1.44 \mathrm{ng} / \mu \mathrm{L}$ thiamethoxam decreased larval survival, and the concentrations of 1.44 and 

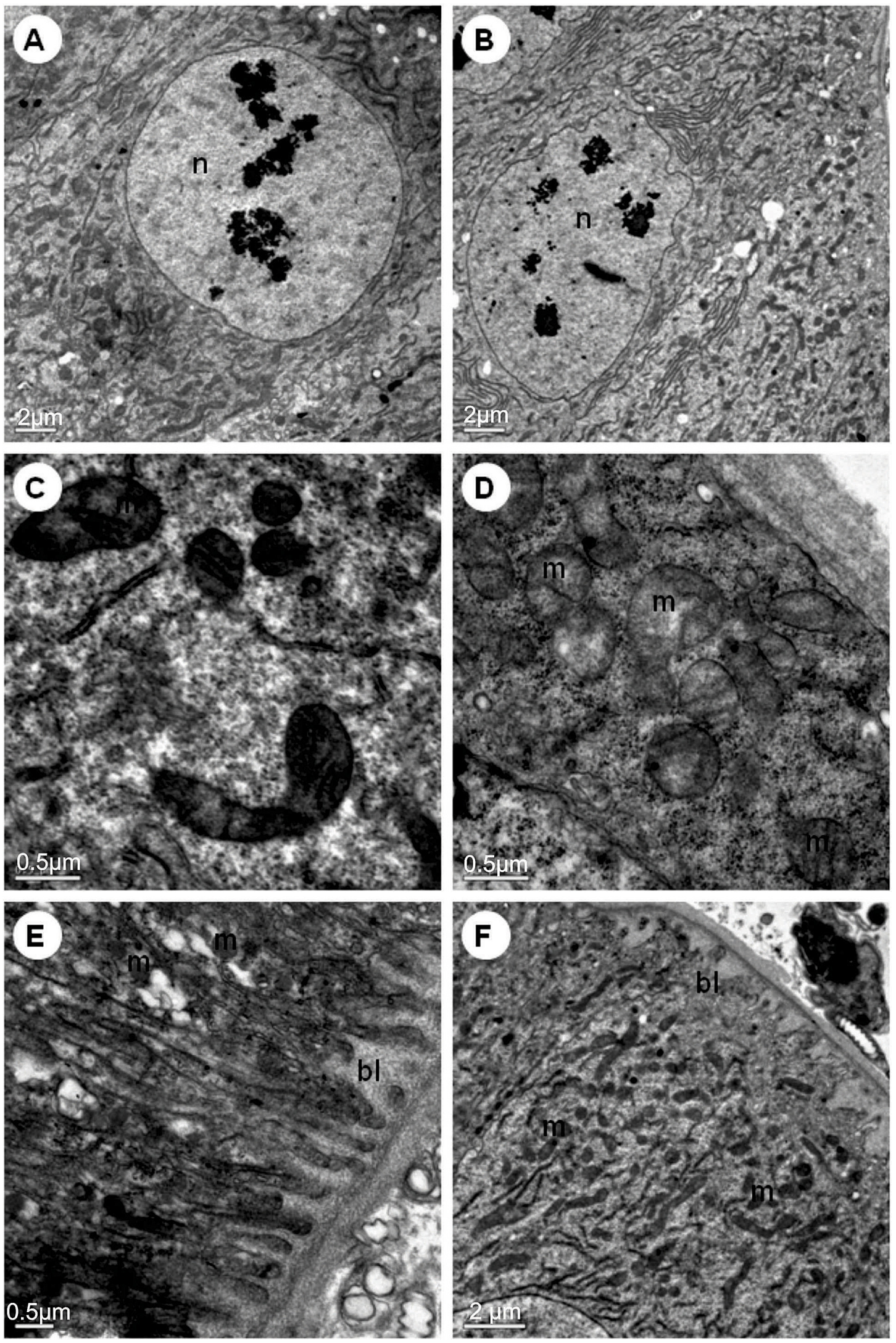

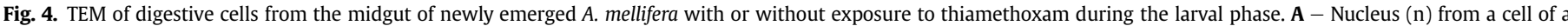

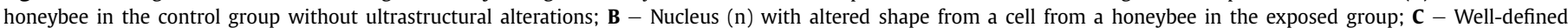

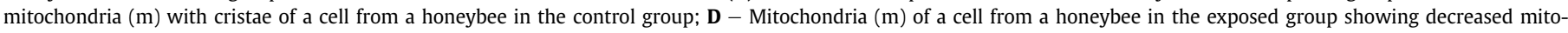

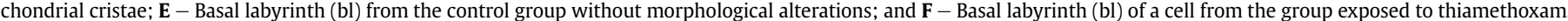
showing the loss of long and thin channels. 

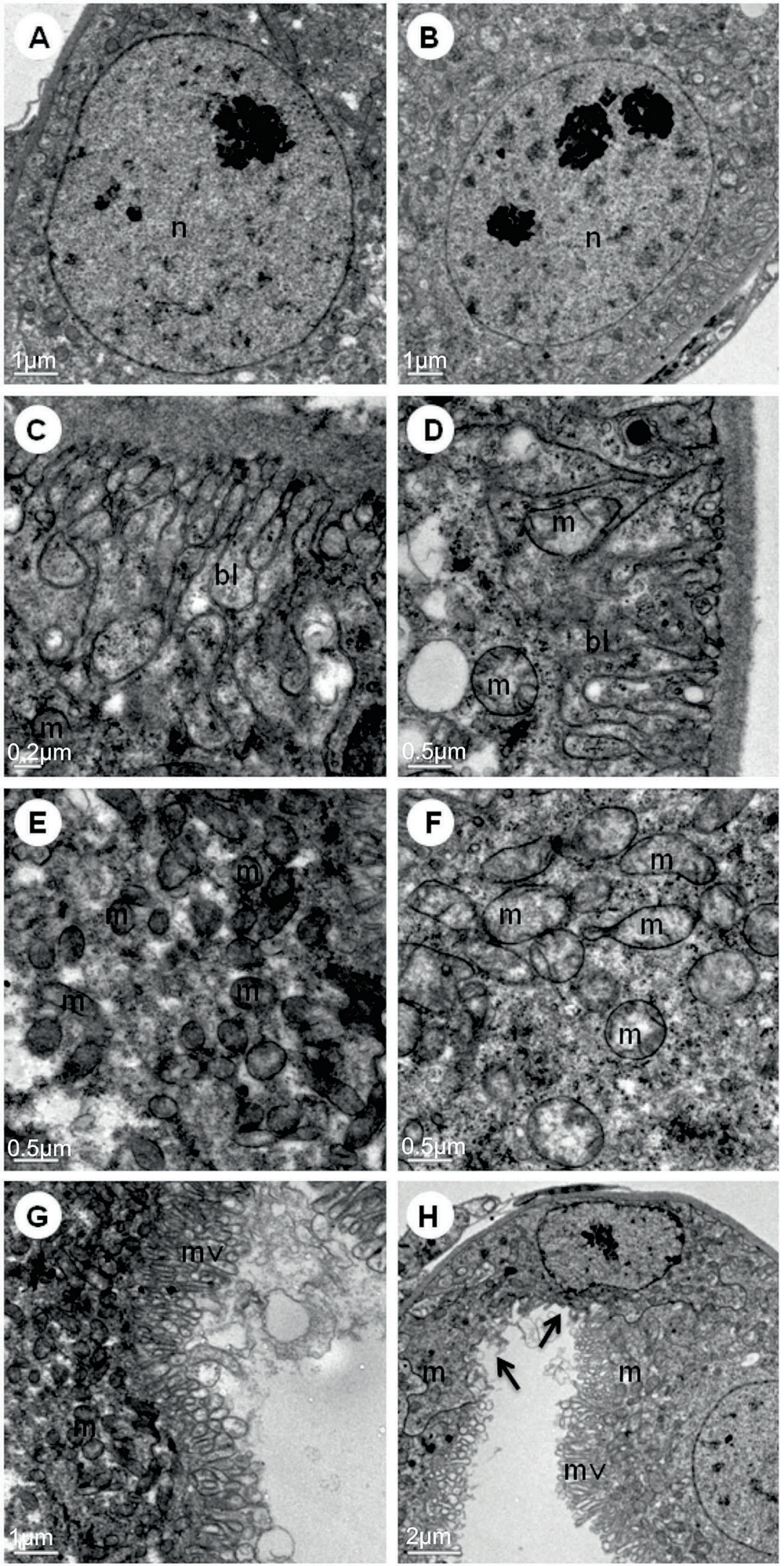

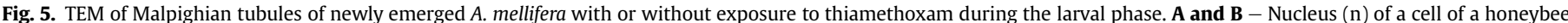

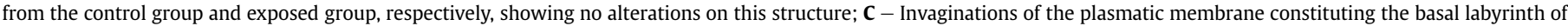

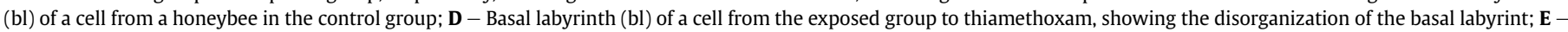

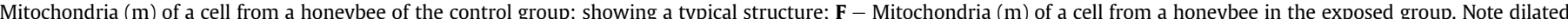

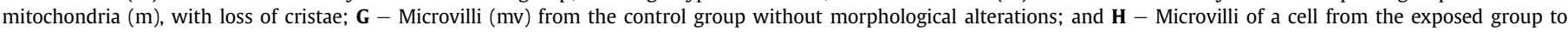
thiamethoxam, showing that part of the microvilli is lost (arrows). 

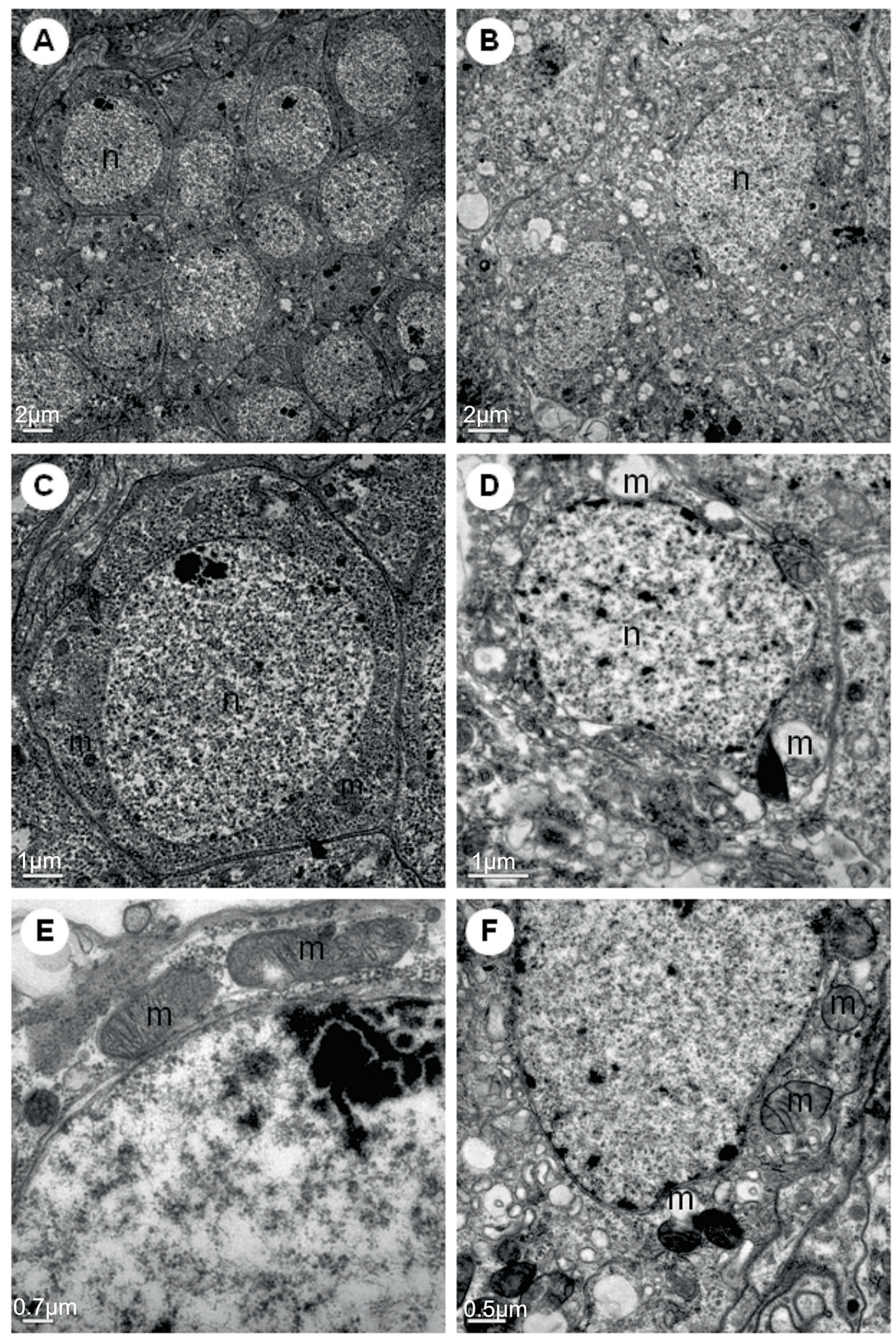

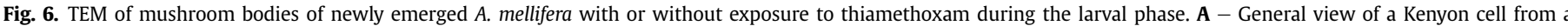

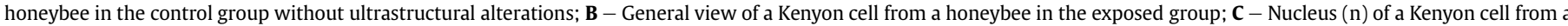

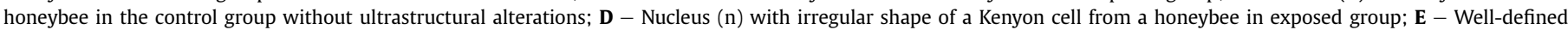

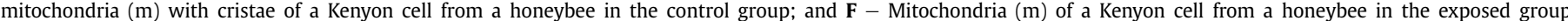
showing the loss of some cristae. 
$0.01 \mathrm{ng} / \mu \mathrm{L}$ thiamethoxam decreased pupae survival and influenced the percentage of emerging bees.

There are several studies in the literature regarding the effects of thiamethoxam on adult $A$. mellifera bees, but there is still a lack of studies on the effects of thiamethoxam or other insecticides on the development of A. mellifera (Cousin et al., 2013; Desneux et al., 2007; Yang et al., 2012). Thus, new studies on this subject are necessary in order to understand the mechanisms involved in larval survival and their tolerance to thiamethoxam.

Although there was no interference of the insecticide in the survival of larvae and pupae or in the percentage of adults that emerged, ultrastructural alterations were observed in target and non-target organs of the newly emerged bees after thiamethoxam exposure in the larval stage. These alterations indicate possible tissue degeneration, demonstrating the cytotoxicity of thiamethoxam in the target and non-target organs of newly emerged bees that can compromise cellular function, showing that even though it does not cause changes in survival, field concentrations of this insecticide causes cellular alterations in the bees' organs, which may compromise their viability.

It could be that the concentration of $0.001 \mathrm{ng} / \mu \mathrm{L}$ thiamethoxam that was administered during the larval development in vitro was low and could not interfere with larval survival and metamorphosis, or larvae may be more tolerant to the insecticide than adult bees. However, in the newly emerged phase, ultrastructural alterations were observed in the organs of these bees, possibly indicating that the transition stages may be vulnerable to insecticides, thus leading to alterations in adulthood.

Zhu et al. (2014) studied the effects of chronic exposure of A. mellifera larvae to environmental doses of fluvalinate, coumafos, chlorothalonil, and chlorpyrifos. They showed that the unconventional response to toxicity may be a consequence of the time required to accumulate internal concentrations of the insecticide that are sufficient to exert its actions on the targets present in the central nervous system of bees.

Thus, although the concentration of $0.001 \mathrm{ng} / \mu \mathrm{L}$ did not alter the survival of the larvae, they may have accumulated the insecticide to levels that were able to cause alteration in the bees' organs in the newly emerged phase.

Yang et al. (2012) exposed A. mellifera larvae to $0.04 \mathrm{ng}$ of imidacloprid and found that although this dose did not cause larval mortality, it affected memory and learning when they emerged as adult bees. Thus, although larvae appear to be more tolerant to neonicotinoids than adult bees, adverse effects may occur in later stages of development as a result of exposure during the larval period.

Thus, it is important to analyze the cytotoxicity of thiamethoxam in target and non-target organs of newly emerged bees after exposure to this compound during the larval phase.

Considering that neonicotinoids have a systemic action, all parts of the plant as well as nectar and pollen contain residual traces of these products (Blacquière et al., 2012); hence, bees can be contaminated through food collection. When the contaminated food is ingested, it comes into contact with the midgut.

This organ, even though it is a non-target organ, can also be affected by the insecticide since it is involved in the metabolism of the compound. The midgut, according to Cruz-Landim (2009), is the portion of the digestive tract that is responsible for most of the digestion and absorption of food and is considered the functional stomach in insects.

Ultrastructural alterations could be observed in the digestive cells of midgut of newly emerged $A$. mellifera bees after exposure to thiamethoxam during the larval phase. Bees are holometabolous insects and therefore undergo a complete reorganization of organs during metamorphosis, i. e., during pupae phase. In Hymenoptera changes in the midgut begin in the prepupa with the larval epithelium degenerating, leaving only the basement membrane and the regenerative cells. At metamorphosis the larval midgut epithelium is reabsorbed and substituted for cells from regenerative cells (Cruz Landim, 2009). So, the insecticide intake during the larval phase probably is cytotoxic to the regenerative cells in the larval phase. This toxicity reflected in alteration in their differentiation in digestive cells during the metamorphosis. As a consequence, newly emerged bees, showed digestive cells with ultrastructural alteration.

In this way, bees of the exposed group presented a basal labyrinth without long and thin channels and compromised mitochondria with a loss of cristae and matrix.

It is known that in the digestive cells of the midgut of the insects, the folds of the basolateral membranes form fine and long channels with adhered particles on their cytoplasmic side (Terra, 1988); these characteristics were observed in the control group (Santos et al., 1984). These folds of membranes contribute to the concentration of solutes, thus generating an osmotic gradient between the lumen and the compartment and favoring the water absorption (Terra et al., 2006). The basolateral membranes, in addition to their involvement with the trans-epithelial transport of water and solutes, may also possess other functions such as hemolymph trehalose digestion (Azuma and Yamashita, 1985).

Thus, these membrane folds are of great importance to the physiology of digestive cells in the midgut. The absence of these long and thin channels in the basal labyrinth, which was observed in the present study within the digestive cells of midgut of exposed bees, may interfere with water absorption, the trans-epithelial transport of water and solutes, and hemolymph trehalose digestion. The absence of long and thin channels can occur due to a loss or reduction of the basal labyrinth and may indicate possible tissue degeneration, thus demonstrating the cytotoxicity of thiamethoxam to this organ.

In addition, the group exposed to the insecticide showed mitochondria with ultrastructural alterations, which demonstrate that the metabolic ability of this organelle may be altered by thiamethoxam.

The morphology and quantity of cristae in the mitochondria are reflective of the organelle's energy demand (Scheffler, 1999; Mannella, 2006; Zick et al., 2009). Thus, considering the importance of these cellular structures, the loss of cristae and matrix in the group exposed to thiamethoxam suggests a lack of energy demand and may cause compromised mitochondrial functions.

Catae et al. (2014) observed the effects of a sublethal dose of thiamethoxam on the midgut of Africanized A. mellifera and verified through ultrastructural analysis that bees exposed for 1 day to the insecticide presented digestive cells with alterations in several organelles. The mitochondria exhibited a decrease in cristae, the rough endoplasmic reticulum showed dilated cisterns that were disorganized and had a smaller number of ribosomes, and the nuclei of these cells were irregular, demonstrating that this neonicotinoid causes alterations in the midgut of these insects, compromise the cell organelles, and alter the physiology of these cells.

In the body of the bee, following the metabolism of thiamethoxam, the digested products or the undigested molecule will reach the hemolymph and, subsequently, the brain (target organ of the insecticide) and the Malpighian tubules. This organ is responsible for the maintenance of homeostasis and for the detoxification process that eliminates excess substances, even those that have not been metabolized by the body (Chapman, 1998).

Ultrastructural alterations were also observed in the Malpighian tubules of exposed bees. Bees in the group exposed to thiamethoxam exhibited tubules with a disorganized basal labyrinth. 
According to Cruz-Landim (2009), the basal labyrinth, in the Malpighian tubules, is a structure that is responsible for optimizing the uptake of metabolized substances and for promoting greater contact with hemolymph. Therefore, it is evident that the function of the basal labyrinth has been compromised in the group exposed to thiamethoxam, and these changes had potentially damaged the excretory ability of the Malpighian tubules.

In the Malpighian tubules of the exposed bees, the mitochondria were dilated, exhibited a loss of cristae, and possessed a distorted shape. Mitochondrial alterations may have been caused "directly or indirectly" by neonicotinoid. According to Nicodemo et al. (2014) imidacloprid, other insecticide of neonicoitinoid class, affects the stage 3 of the cellular respiration process, inhibiting the production of ATP. Mitochondrial alterations observed may have seriously compromised mitochondrial function. Thus, the alterations observed in these organelles in the exposed group are highly detrimental to the whole structure of the organ, interfering in the performance of its normal functions, such as ATP production, and preventing them from performing the metabolic activities that the cells need to survive.

Catae et al. (2014) found that on the first day the Africanized bees were exposed to thiamethoxam, the Malpighian tubules exhibited a disorganized basal labyrinth. On the fifth day of exposure, there were alterations in the basal labyrinth as well as the presence of very dilated mitochondria and some alterations in the microvilli. On the eighth day of exposure, there was an almost complete loss of the basal labyrinth of the Malpighian tubules and nuclei with condensed chromatin; additionally, the apical portion of the microvilli was dilated.

Considering that bees are holometabolous insects, the insecticide intake by the larvae was stored in the fat body, may be inactivated, since the larva is not affected. As the fat body cells are broken during metamorphosis for release the energetic compounds used in the insect post-embryonic development (Cruz Landim, 2009), the insecticide might be liberated in the haemolimph. Then this compound can reach the brain and the Malpighian tubules affecting their cells morphology. The larval Malpighian tubules are totally reabsorbed and new ones arise during pupation to function in adult (Cruz Landim, 2009). So, during the metamorphosis when the insecticide is released to the haemolimph, it can reach the Malpighian tubules affecting their differentiation and cells morphology. The same occurs to the brain, which structure is reorganized during metamorphosis by neurons proliferation and differentiation.

Ultrastructural alterations were observed in the brain; more specifically, in the mushroom body of newly emerged A. mellifera bees that were exposed to thiamethoxam during the larval stage.

In the present study, the mushroom bodies deserved attention for being related to learning and memory in the bees (Daly et al.,1998; Cruz-Landim, 2009). In insects, these brain regions are centers of multimodal integration and are thus responsible for both receiving and interpreting all of the mechanosensory, gustatory, visual and olfactory information (Zars, 2000; Komischke et al., 2005; Kiya et al., 2007).

The mushroom bodies of bees in the exposed group presented Kenyon cells with modified cytoplasm, the presence of digestive vacuoles, and the impairment of mitochondria, where cristae loss was observed.

Decourtye et al. (2004) observed an increase in the activity of the enzyme cytochrome oxidase (CO) in the mushroom bodies of A. mellifera worker bees that were exposed to imidacloprid. In the process of mitochondrial respiration, $\mathrm{CO}$ is the terminal enzyme in the electron transport chain. Nicodemo et al. (2014) also showed that in Africanized bees, fipronil and imidacloprid affect the production of ATP in the brain and are inhibitors of mitochondrial bioenergetics, resulting in the failure of cellular respiration.

Thus, in this study, the ultrastructural alterations observed in mitochondria show that, similar to imidacloprid, which is also a neonicotinoid with neurotoxic actions, thiamethoxam also impairs mitochondrial functions, thus showing that this class of insecticides can change neural activity by increasing cellular respiration.

According to Decourtye et al. (2004), changes in the activity of the central nervous system occur at the same time problems appear in the memory process of the bee. To characterize the brain structures involved in memory processes in invertebrates, the histochemical detection of the enzymatic activity of $\mathrm{CO}$ is considered an important tool (Agin et al., 2001; Déglise et al., 2003; Roat et al., 2013).

In addition, the increase in mitochondrial activity can generate ROS, causing oxidative stress in the cells. During the reduction of molecular oxygen, water and ROS are typically formed during mitochondrial respiration. The accumulation of ROS causes damages to cells, carbohydrates, lipids, proteins and nucleic acids (Trushina and Mcmurray, 2007; Halliwell and Gutteridge, 2015).

The cellular degeneration promoted by oxidative stress occurs because of the cytotoxic effects of ROS, which include superoxide anion $\left(\mathrm{O}_{2}\right)$, hydroxyl radical $(\mathrm{OH})$ and hydrogen peroxide $\left(\mathrm{H}_{2} \mathrm{O}_{2}\right)$ (Gutteridge, 1994; Barbosa et al., 2006; Halliwell and Gutteridge, 2015).

In the present study, the cytotoxic effects, both the EROs and the neurotoxic effect of thiamethoxam, can also be seen in the ultrastructural alterations observed in the nucleus of Kenyon cells. The bees of the exposed group presented Kenyon cells with an irregular nucleus and a dilated perinuclear space. These nuclear alterations signal cell degeneration, which can, along with the mitochondrial impairment, trigger cell death.

The process of cell death can be identified by a series of characteristic cell alterations, such as mitochondrial and nuclear changes (Bowen et al., 1998). According to Häcker (2000); the loss of mitochondrial matrix content can be observed in cells that are undergoing the process of cell death. Inductive signals of cellular death cause alterations in the permeability of the mitochondrial membranes, resulting in the release of cell death-activating proteins to the cytoplasm and the interruption of ATP synthesis (Grivicich et al., 2007; Loeffler and Kroemer, 2000). In this study, exposure of larvae to thiamethoxam caused rather evident ultrastructural changes in the mitochondria of newly emerged worker bees. These evidence in addition to the observed nuclear alterations indicate that these cells are in the early stages of cell death. Changes in nuclear morphology are a typical feature of programmed cell death and are related to the decreased activity of cells that will undergo degeneration (Kerr et al., 1972; Cruz-Landim and Cavalcante, 2003; Silva-Zacarin et al., 2007).

Thereby, it is noticeable that the use of low concentrations of the insecticide thiamethoxam may cause sublethal effects in Africanized A. mellifera. It is worth mentioning that Yang et al. (2008), through behavioral tests, were able to verify that worker bees that were exposed to sublethal doses of imidacloprid also exhibited alterations in their foraging activities. According to Ishaaya et al. (2007), it is probable that the neonicotinoids affect the behavior of the worker bees by directly acting on the acetylcholine and nicotine receptors, which can subsequently cause paralysis, excitement and even death. As the mushroom bodies are associated with both the processes of learning and memory, the damage caused in these structures by several insecticides can lead to disorientation of the bee and can harm their foraging ability, thus jeopardizing the entire colony.

The studies mentioned so far demonstrate that different insecticides can induce sublethal effects in Kenyon cells; however, research on the effects of thiamethoxam exposure during the larval 
stage on the brains of newly emerged bees is still scarce in the literature, making this a pioneer study that showed such effects in the central nervous system and in the non-target organs of Africanized $A$. mellifera bees through ultrastructural analyses. This shows that even in organs that are remodeled during metamorphosis (Cruz-Landim, 2009), the effects of the insecticide are prolonged and remain, allowing for the observation of its consequences in later stages of bee development.

\section{Conclusions}

In general, the results obtained in the present study showed that there was no interference of the insecticide thiamethoxam in the survival of both larvae and pupae as well as in the emergence of adult bees. On the other hand, the digestive cells, Malpighian tubules cells and Kenyon cells of the newly emerged bees after exposure to thiamethoxam during the larval phase showed ultrastructural alterations, demonstrating that even the use of a field dose that is considered low $(0.001 \mathrm{ng} / \mu \mathrm{L})$ can cause serious damages to the cells of these organs, that may interfere with the normal function of them, and may alter the behavior of the insect.

\section{Acknowledgments}

We thank the São Paulo Research Foundation (FAPESP) (grants 2015/09691-1, 2012/13370-8 and 2012/50197-2). We also thank Adna Suelen Dorigo and Hellen Maria Soares Lima for technical support.

\section{References}

Agin, V., Chichery, R., Chichery, M.P., 2001. Effects of learning on cytochrome oxidase activity in cuttlefish brain. NeuroReport 12 (1), 113-116.

Antunes-Kenyon, S.E., Kennedy, G., 2001. Thiamethoxam: a New Active Ingredient Review. Massachusetts Pesticide Bureau, Boston. Department of Food and Agriculture.

Atkins, E.L., Kellum, D., 1986. Comparative morphogenic and toxicity studies on the effect of pesticides on honeybee brood. J. Apic. Res. 25, 242-255.

Aupinel, P., Fortini, D., Dufour, H., Tasei, J.N., Michaud, B., Odoux, J.F., PhamDelègue, M.H., 2005. Improvement of artificial feeding in a standard in vitro method forrearing Apis mellifera larvae. Bull. Insectol. 58, 107-111.

Aupinel, P., Fortini, D., Michaud, B., Marolleau, F., Tasei, J.N., Odoux, J.F., 2007 Toxicity of dimethoate and fenoxycarb to honey bee brood (Apis mellifera) using a new in vitro standardized feeding method. Pest. Manag. Sci. 63, 1090-1094.

Azuma, M., Yamashita, O., 1985. Immunohistochemical and biochemical localization of trehalase in the developing ovaries of the silkworm, Bombyx mori. Insect Biochem. 15, 589-596.

Barbosa, L.F., Medeiros, M.H.G., Augusto, O., 2006. Danos oxidativos e neurodegeneração: o que aprendemos com animais transgênicos e nocautes? Quim. Nova 29 (6), 1352-1360.

Blacquière, T., Smagghe, G., van Gestel, A.M., Mommaerts, V., 2012. Neonicotinoids in bees: a review on concentrations, side-effects and risk assessment. Ecotoxicology 21 (4), 973-992.

Bonmatin, J.M., Moineau, I., Charvet, R., Fleche, C., Colin, M.E., Bengsch, E.R., 2003. A LC/APCI-MS/MS method for analysis of imidacloprid in soils, in plants, and in pollens. Anal. Chem. 75, 2027-2033.

Bowen, I.D., Bowen, S.M., Jones, A.H., 1998. Mitosis and Apoptosis: Matters of Life and Death, first ed. Chapman \& Hall, London, New York.

Catae, A.F., Roat, T.C., Oliveira, R.A., Nocelli, R.C.F., Malaspina, O., 2014. Cytotoxic effects of thiamethoxam in the midgut and malpighian tubules of Africanized Apis mellifera (Hymenoptera: Apidae). Microsc. Res. Tech. 77, 274-281.

Chapman, R.F., 1998. The Insects: Structure and Function, fourth ed. Cambridge Universities Press, New York.

Colin, M.E., Bonmatin, J.M., Moineau, I., Gaimon, C., Brun, S., 2004. A method to quantify and analyze the foraging activity of honey bees: relevance to the sublethal effects induced by systemic insecticides. Arch. Environ. Contam. Toxicol. 47, 387-395.

Cousin, M., Silva-Zacarin, E.C.M., Kretzschmar, A., El Maataoui, M., Brunet, J.L., Belzunces, L.P., 2013. Size changes in honey bee larvae oenocytes induced by exposure to Paraquat at very low concentrations. PLoS One 8, e65693.

Cruz, A.S., Silva- Zacarin, E.C.M., Bueno, O.C., Malaspina, O., 2010. Morphologica alterations induced by boric acid and fipronil in the midgut of worker honeybee (Apis mellifera L.) larvae. Cell. Biol. Toxicol. 26, 165-179.

Cruz-Landim, C., 2009. Abelhas: Morfologia e função de sistemas, primeira edição.
UNESP, São Paulo.

Cruz-Landim, C., Cavalcante, V.M., 2003. Ultrastructural and cytochemical aspects of metamorphosis in the midgut of Apis mellifera L. (Hymenoptera: Apidae: Apinae). Zool. Sci. 20 (9), 1099-1107.

Daly, V.H., Doyen, J.T., Purcell III, A.H., 1998. Introduction to Insect Biology and Diversity, second ed. Oxford University Press, New York.

Davis, R.L., 2001. Mushroom bodies, Ca2+ oscillations, and the memory gene amnesiac. Neuron 30, 653-656.

Decourtye, A., Lacassie, E., Pham-Delègue, M.H., 2003. Learning performances of honeybees (Apis mellifera L) are differentially affected by imidacloprid according to the season. Pest. Manag. Sci. 59, 269-278.

Decourtye, A., Armengaud, C., Renou, M., Devillers, J., Cluzeau, S., 2004. Imidacloprid impairs memory and brain metabolism in the honeybee (Apis mellifera L.). Pest. Biochem. Physiol. 78, 83-92.

Déglise, P., Dacher, M., Dion, E., Gauthier, M., Armengaud, C., 2003. Regional brain variations of cytochrome oxidase staining during olfactory learning in the honeybee (Apis mellifera). Behav. Neurosci. 117 (3), 540-547.

Desneux, N., Decourtye, A., Delpuech, J.L., 2007. The subletal effects of pesticides on beneficial arthropods. Annu. Rev. Entomol. 52, 81-106.

Di Prisco, G. Cavaliere, V., Annoscia, D., Varricchio, P., Caprio, E., Nazzi, F. Gargiulo, G., Pennacchio, F., 2013. Neonicotinoid clothianidin adversely affects insect immunity and promotes replication of a viral pathogen in honey bees. Proc. Natl. Acad. Sci. 110, 18466-18471.

Fahrbach, S., 2006. Structure of the mushroom bodies of the insect brain. Annu. Rev. Entomol. 51, 209-232.

Faria, A.B.C., 2009. Revisão sobre alguns grupos de inseticidas utilizados no manejo integrado de pragas florestais. Ambiência 5 (2), 345-358.

Farris, S.M., 2005. Evolution of insect mushroom boddies: old clues, new insights. Arthropod Struct. Dev. 34 (3), 211-234.

Gerber, B., Tanimoto, H., Heisenberg, 2004. An engram found? Evaluating the evidence from fruit flies. Curr. Opin. Neurobiol. 14 (6), 737-744.

Goulson, D., Nicholls, E., Botías, C., Rotheray, E.L., 2015. Bee declines driven by combined stress from parasites, pesticides, and lack of flowers. Science 347. http://dx.doi.org/10.1126/science.1255957.

Grivicich, I., Regner, A., Rocha, A.B., 2007. Morte celular por apoptose. Rev. Bras. Cancerol. 53 (3), 335-343.

Gutteridge, J.M., 1994. Hydroxyl radicals, iron, oxidative stress, and neurodegeneration. Ann. N. Y. Acad. Sci. 738, 201-213.

Häcker, G., 2000. The morphology of apoptosis. Cell Tissue Res. 301, 5-17.

Halliwell, B., Gutteridge, J.M.C., 2015. Free Radicals in Biology and Medicine, fifth ed. Oxford University Press, New York.

Henry, M., Béguin, M., Requier, F., Rollin, O., Odoux, J.F., Aupinel, P., Aptel, J., Tchamitchian, S., Decourtye, A., 2012. A common pesticide decreases foraging success and survival in honey bees. Science 336 (6079), 348-350.

Ishaaya, I., Barazani, A., Kontsedalov, S., Horowitz, A.R., 2007. Insecticides with novel modes of action: mechanism, selectivity and cross-resistence. Entomol. Res. 37 (3), 148-152.

Jacob, C.R.O., Soares, H.M., Nocelli, R.C.F., Malaspina, O., 2014. Impact of fipronil on the mushroom bodies of the stingless bee Scaptotrigona postiça. Pest. Manag. Sci. http://dx.doi.org/10.1002/ps.3776.

Kakamand, F.A.H. Mahmoud, T.T, Amin, A.B.M., 2008. The role of three insecticides in disturbance the midgut tissue in honey bee Apis mellifera L. workers. J. Duhok Univ. 11 (1), 144-151.

Kerr, J.F., Wyllie, A.H., Currie, A.R., 1972. Apoptosis: a basis biological phenomenon with wide-ranging implications in tissue kinetics. Br. J. Cancer 26 (4), 239-257.

Kiya, T., Kunieda, T., Kubo, T., 2007. Increased neural activity of a mushroom body neuron subtype in the brains of forager honeybees. PLos One 2 (4), e371.

Komischke, B., Sandoz, J.C., Malun, D., Giurfa, M., 2005. Partial unilateral lesions of the mushroom bodies affect olfactory learning in honeybees Apis mellifera L. Eur. J. Neurosci. 20, 477-485.

Krupke, C.H., Hunt, G.J., Eitzer, B.D., Andino, G., Given, K., 2012. Multiple routes of pesticide exposure for honey bees. PLos One 7 (1), 1-8.

Liu, L., Wolf, R., Ernst, R., Heisenberg, M., 1999. Context generalization in Drosophila visual learning requires the mushroom bodies. Nature 400, 753-756.

Loeffler, M., Kroemer, G., 2000. The mitochondrion in cell death control: certainties and incognita. Exp. Cell Res. 256 (1), 19-26.

Mannella, C.A., 2006. The relevance of mitochondrial membrane topology to mitochondrial function. Biochim. Biophys. Acta 1762, 140-147.

Mizunami, M., Weibrecht, J.M., Strausfeld, N.J., 1993. A new role for the insect mushroom bodies: place memory and motor control. In: Beer, R.D. Ritzman, R.E., McKenna, T. (Eds.), Biological Neural Networks in Invertebrate Neuroethology and Robotics. Academic Press, New York, pp. 199-225.

Mullin, C.A., Frazier, M., Frazier, J.L., Ashcraft, S., Simonds, S., vanEngelsdorp, D., Pettis, J.S., 2010. High levels of miticides and agrochemicals in North American apiaries: implications for honey bee health. PLoS One 5, e9754.

Neumann, P., Carreck, N., 2010. Honey bee colony losses. J. Apic. Res, 49, 1-6.

Neves, C.A., Serrão, J.E., Gitirana, L.B., 2003. Ultrastructural study of the metamorphosis in the midgut of Melipona quadrifasciata anthidioides (Apidae, Meliponini) worker Sociobiology 41, 443-459.

Nicodemo, D., Maioli, M.A., Medeiros, H.C.D., Guelfi, M., Balieira, K.V.B., Jong, D., Mingatto, F.E., 2014. Fipronil and imidacloprid reduce honeybee mitochondrial activity. Environ. Toxicol. Chem. 33 (9), 2070-2075.

Nondillo, A. Zanardi, O., Afonso, A.P.S., Benedetti, A.J., Botton, M., 2007. Efeito de inseticidas neonicotinóides sobre a mosca-das-frutas sul-Americanas Anasttrepha fraterculus (Wiedemann) (Diptera: Tephritidae) na cultura da videira. 
BioAssay 2 (9), 1-9.

OECD, 2013. Guidelines for the Testing of Chemicals, Honey Bee (Apis mellifera) Larval Toxicity Test, Single Exposure No. 237.

Oliveira, R.A., Roat, T.C., Carvalho, S.M., Malaspina, O., 2013. Side-effects of thiamethoxam on the brain and midgut of the africanized honeybee Apis mellifera (Hymenopptera: Apidae). Environ. Toxicol. 29, 1122-1133.

Pilling, E., Campbell, P., Coulson, M., Ruddle, N., Tornier, I., 2013. A four-year field program investigating long-term effects of repeated exposure of honey bee colonies to flowering crops treated with thiamethoxam. PLoS One 8, e77193.

Potts, S.G., Biesmeijer, J.C., Kremen, C., Neumann, P., Schweiger, O., Kunin, W.E., 2010. Global pollinator declines: trends, impacts and drivers. Trends Ecol. Evol. $25,345-353$.

Potts, S.G., Imperatriz-Fonseca, V., Ngo, H.T., Aizen, M.A., Biesmeijer, J.C., Breeze, T.D. Dicks, L.V., Garibaldi, L.A., Hill, R., Settele, J., Vanbergen, A.J., 2016. Safeguarding pollinators and their values to human well-being. Nature 540 (7632), 220-229.

R Development Core Team, 2015. R: A Language and Environment for Statistical Computing. R Foundation for Statistical Computing, Vienna: Austria. ISBN 3900051-07-0 http://www.R-project.org.

Rancan, M., Rossi, S., Sabatini, A.G., 2006. Determination of thiamethoxam residues in honeybees by high performance liquid chromatography with an electrochemical detector and post-column photochemical reactor. J. Chromatogr. 1123 (1), 60-65.

Roat, T.C., Carvalho, S.M., Nocelli, R.C.F., Silva-Zacarin, E.C.M., Palma, M.S., Malaspina, O., 2013. Effects of sublethal dose of fipronil on neuron metabolic activity of africanized honeybees. Arch. Environ. Contam. Toxicol. 63, 1-11.

Rortais, A., Arnold, G., Halm, M.P., Touffet-Briens, F., 2005. Modes of honeybees exposure to systemic insecticides: estimated amounts of contaminated pollen and nectar consumed by different categories of bees. Apidologie 36, 71-83.

Santos, C.D., Ribeiro, A.F., Ferreira, C., Terra, W.R., 1984. The larval midgut of the cassava hornworm (Erinnyis ello). Ultrastructure, fluid fluxes and the secretory activity in relation to the organization of digestion. Cell Tissue Res. 237, 565-574.

Scheffler, I.E., 1999. Mitochondria, first ed. Wiley-Liss, New York.

Schneider, C.W., Tautz, J. Grünewald, B.,Fuchs, S., 2012. RFID tracking of sublethal effects of two neonicotinoid insecticides on the foraging behavior of Apis mellifera. PLoS One 7 (1), e30023.
Silva-Zacarin, E.C.M., Tomaino, G.A., Brocheto-Braga, M.R., Taboga, S.R., De Moraes, R.S., 2007. Programmed cell death in the larval salivary glands of Apis mellifera (Hymenoptera, Apidae). J. Biosci. 32 (2), 309-328.

Stoner, K.A., Eitzer, B.D., 2012. Movement of soil-applied imidacloprid and thiamethoxam into nectar and pollen of squash (Cucurbita pepo). PLoS One 7 e39114.

Tavares, D.A., Roat, T.C., Carvalho, S.M., Silva-Zacarin, E.C.M., Malaspina, O., 2015 In vitro effects of thiamethoxam on larvae of Africanized honey bee Apis mellifera (Hymenoptera: Apidae). Chemosphere 135, 370-378.

Terra, W.R., 1988. Physiology and biochemistry of insect digestion: an evolutionary perspective. Braz. J. Med. Biol. Res. 21, 675-734.

Terra, W.R., Costa, R.H., Ferreira, C., 2006. Plasma membranes from insect midgut cells. An. Acad. Bras. Cienc 78, 255-269.

Tomizawa, M., Casida, J.E., 2003. Selective toxicity of neonicotinoids attributable to specificity of insect and mammalian nicotinic receptors. Annu. Rev. Entomol. 48 339-364.

Trushina, E., Mcmurray, C.T., 2007. Oxidative stress and mitochondrial dysfunction in neurodegenerative diseases. Neuroscience 145 (4), 1233-1248.

vanEngelsdorp, D., Meixner, M.D., 2010. A historical review of managed honey bee populations in Europe and the United States and the factors that may affect them. J. Invert. Pathol. 103, 80-95.

Waller, G.D., Barker, R.J., Martin, J.H., 1979. Effects of dimethoate on honeybee foraging. Chemosphere 7, 461-463.

Yang, E.C., Chuang, Y.C., Chen, Y.L., Chang, L.H., 2008. Abnormal foraging behavior induced by sublethal dosage of imidacloprid in the honey bee (Hymenoptera: Apidae). J. Econ. Entomol. 101 (6), 1743-1748.

Yang, E.C., Chang, H.C., Wu, W.Y., Chen, Y.W., 2012. Impaired olfactory associative behavior of honeybee workers due to contamination of imidacloprid in the larval stage. PLoS One 7, e49472.

Zars, T., 2000. Behavioral functions of the insect mushroom bodies. Curr. Opin. Neurobiol. 10 (6), 790-795.

Zhu, W., Schmehl, D.R., Mullin, C.A., Frazier, J.L., 2014. Four common pesticides, their mixtures and a formulation solvent in the hive environment have high oral toxicity to honey bee larvae. PLoS One 9, e77547.

Zick, M., Rabl, R., Reichert, A.S., 2009. Cristae formationlinking ultrastructure and function of mitochondria. Biochim. Biophys. Acta 1793 (1), 5-19. 